\title{
18F-FDG PET-CT in adult-onset Still's disease mimics malignant lymphoma
}

\author{
Hayato Shimizu $^{1}$, Shuji Sumitomo ${ }^{1}$, and Nishioka Hiroaki ${ }^{1}$ \\ ${ }^{1}$ Kobe City Medical Center General Hospital
}

November 6, 2020

\begin{abstract}
There are no specific serological markers or imaging techniques for Adult-onset Still's disease (AOSD) diagnosis. It is essential to rule out other diseases, especially malignant lymphoma, because both diseases sometimes show similar clinical presentations. However, unfortunately, this case showed PET-CT findings in AOSD patients could mimic those in malignant lymphoma.
\end{abstract}

\section{Hosted file}

CCR(Shimizu)2020.pdf available at https://authorea.com/users/373571/articles/491228-18f-fdgpet-ct-in-adult-onset-still-s-disease-mimics-malignant-lymphoma 


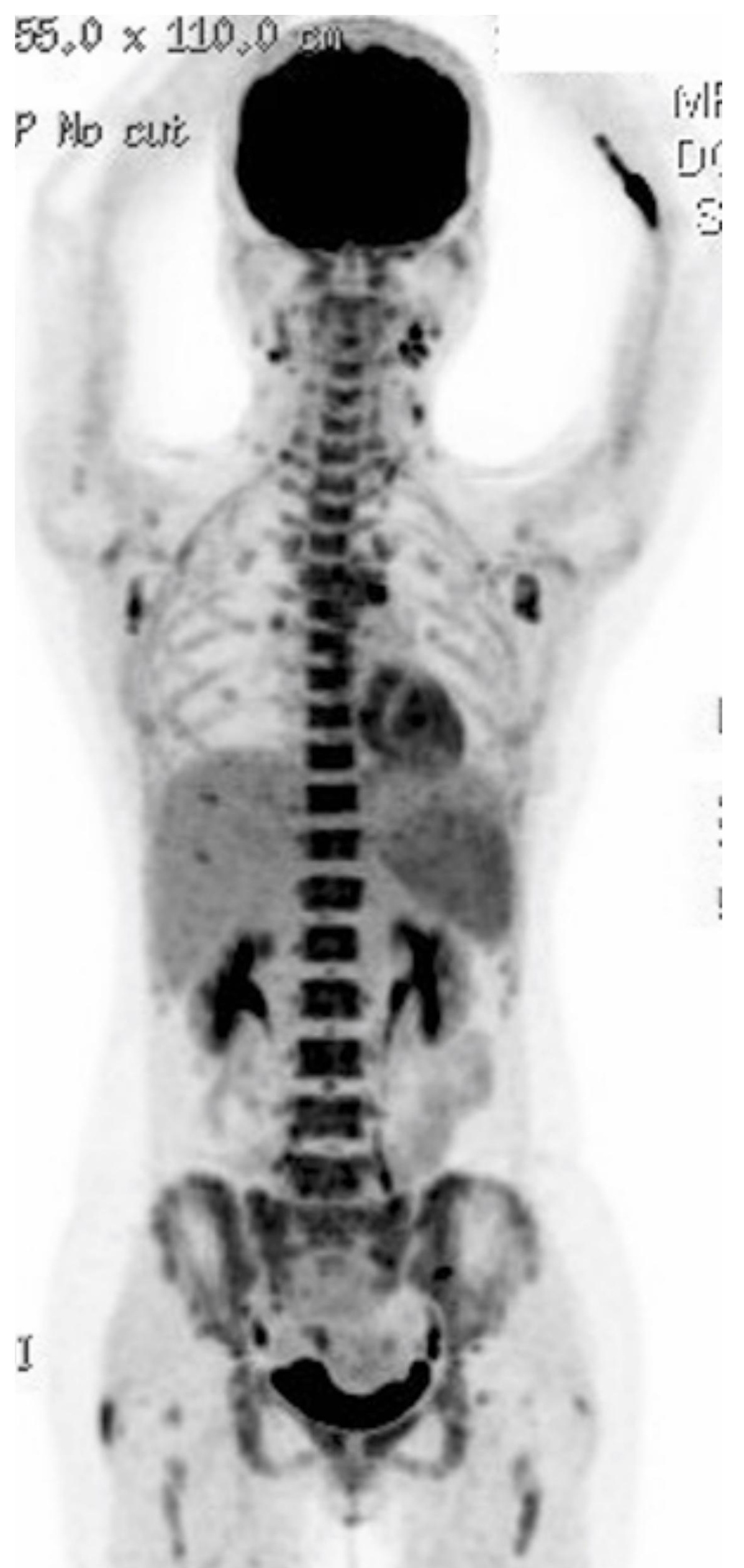

